\title{
Intestinal parasites in children hospitalized at the Central Hospital in Maputo, Mozambique
}

\author{
Ana Maria Fonseca ${ }^{1,2}$, Natércia Fernandes ${ }^{3}$, Filipa S. Ferreira ${ }^{1}$, Joana Gomes ${ }^{1}$, Sónia Centeno-Lima $^{1}$ \\ ${ }^{1}$ Unidade de Clínica Tropical, Instituto de Higiene e Medicina Tropical, Universidade Nova de Lisboa, Portugal \\ ${ }^{2}$ Graduated Program in Areas of Basic and Applied Biology, Instituto de Ciências Biomédicas Abel Salazar, \\ Universidade do Porto, Portugal \\ ${ }^{3}$ Faculdade de Medicina, Universidade Eduardo Mondlane, Maputo, Mozambique
}

\begin{abstract}
Introduction: Intestinal parasites are important contributors to the global disease burden, especially in children of low-income countries. The present study determined the frequency of intestinal parasites in children hospitalized at the diarrhea section of the Infectious-Contagious Diseases ward and at the Malnutrition ward of the Department of Pediatrics of the Maputo Central Hospital in Mozambique.

Methodology: This pilot study conducted between February and March 2009 enrolled a total of 93 children between 1.5 and 48.2 months of age; $87.1 \%$ were younger than 24 months. Parasite detection in stool samples was achieved using direct microscopic observation and Ritchie's concentration technique.

Results: Infection with pathogenic intestinal parasites was detected in 16.1\% (15/93) of the children. Giardia duodenalis and Trichuris trichiura were the most common parasites (6.5\%, 6/93 each), followed by Ascaris lumbricoides (2.2\%, 2/93). One case of mixed infection with A. lumbricoides plus $T$. trichiura was also detected.

Conclusion: This study reinforces the importance of routinely examining stool samples for the diagnosis of intestinal parasites (including protozoa) in children hospitalized in endemic areas.
\end{abstract}

Key words: intestinal parasites; children; Mozambique

J Infect Dev Ctries 2014; 8(6):786-789. doi:10.3855/jidc.3916

(Received 25 June 2013 - Accepted 15 January 2014)

Copyright (C) 2014 Fonseca et al. This is an open-access article distributed under the Creative Commons Attribution License, which permits unrestricted use, distribution, and reproduction in any medium, provided the original work is properly cited.

\section{Introduction}

According to World Health Organization every year there are approximately 1.7 billion cases of diarrheal diseases. Diarrheal disease is the second leading cause of death in children under five years of age, killing around 760,000 children each year [1]. In Mozambique, childhood diarrhea and malnutrition constitute an important health problem, and access to adequate water and sanitation is still limited [2,3].

Diarrhea can be related to a wide range of bacteria, viruses, and intestinal parasites [4]. Infection with intestinal parasites, both protozoa and helminths, is often associated with diarrhea, but also with growth impairment (both physical and intellectual development) and worsening of nutritional status, especially during infancy [4-6].

Studies performed in Mozambique concerning the prevalence of intestinal parasites are scarce. A hospital-based study in a rural area of Mozambique, focusing on children under five years of age with diarrhea, detected a prevalence of $14.4 \%$ for intestinal parasites [7], while other surveys of intestinal parasites in school-aged children (non-hospitalized) revealed a much higher prevalence [8-10]. These data from Mozambique are in accordance with the results obtained in a study performed in Kenya (where hospitalized children under five years of age showed a $20.1 \%$ prevalence for intestinal parasites) [11], in Senegal (where $14 \%$ of children between one month and five years of age from a primary health care institution in an urban area had intestinal parasites) [12], and in Ethiopia (where $37.4 \%$ of students between 6 and 19 years of age had intestinal parasites) [13].

The aim of the present work was to investigate the frequency of intestinal parasites in children hospitalized in the diarrhea section of the InfectiousContagious Diseases ward (ICD) and in the Malnutrition (MN) ward of the Department of Pediatrics of the Maputo Central Hospital in Mozambique. 


\section{Methodology}

A pilot study was conducted between February and March 2009, using a convenience sample of 93 children interned in the two wards (40 from ICD and 53 from MN).

Stool samples were collected by the parents or guardians of the child according to given instructions and placed into a sterile stool container. One stool sample was collected per child, without any pharmacologic induction. Parasite detection was performed through direct microscopic observation of stool samples in saline solution and using Ritchie's concentration technique [14]. The detection and identification of parasites was conducted at the parasitology laboratory at the Faculty of Medicine of the Eduardo Mondlane University of Mozambique.

The study was approved by the Mozambican National Bioethics Committee for Health in December 2008. Oral informed consent was obtained from all the legal parents or guardians of the enrolled children. Only those children whose legal parents or guardians agreed to participate in the study were included.

\section{Results}

The age of the 93 children included in this study ranged from 1.5 to 48.2 months; $87.1 \%$ (81/93) were less than 24 months, and 51.6\% (48/93) less than 12 months of age. Boys accounted for $64.5 \%$ (60/93) of the children. The overall prevalence of intestinal parasites was $16.1 \%$ (15/93). Altogether, Giardia duodenalis was detected in $6.5 \%$ (6/93), Trichuris trichiura in 6.5\% (6/93), and Ascaris lumbricoides in $2.2 \%(2 / 93)$ of the children. One case of mixed infection with $A$. lumbricoides and $T$. trichiura was also detected.

The highest infection prevalence was found at the ICD ward $(22.5 \%, 9 / 40)$, while the $\mathrm{MN}$ ward presented half of this value $(11.3 \%, 6 / 53)$ (Table 1$)$. Helminths were more frequent in the ICD ward, and protozoans were more frequent in the $\mathrm{MN}$ ward. Older children were infected with more parasites than the younger children (50\% [> 24 months] vs. $12.1 \%$ [1224 months] and 10.4\% [0-12 months]) (Table 2).

\section{Discussion}

In the present study, 93 stool samples from children hospitalized in the Central Hospital of Maputo, Mozambique, were analysed through microscopy. Fifteen of the children (16.1\%) were found to be carrying at least one pathogenic intestinal parasite. Our results are similar to those reported in a previous study of hospitalized children (mean age 13.1 months) performed in a rural area of Mozambique and also using microscopy for parasite detection (14.4\%) [7].

Regarding the proportion of parasite distribution by the age groups, the present work showed that half of the children older than 24 months of age were infected. It is known that older children have higher infection rates of parasites because they are more exposed to parasite-prone environments, such as contaminated soil and water, and thus more likely to

Table 1. Intestinal parasitic infections found in 93 children hospitalized at the diarrhea section of the Infectious-Contagious Disease (ICD) and Malnutrition (MN) wards

\begin{tabular}{lccc}
\hline & ICD & MN & Total \\
$(\mathbf{n}=\mathbf{4 0})$ & $(\mathbf{n}=\mathbf{5 3})$ & $2.2 \%(2 / 93)$ \\
\hline Ascaris lumbricoides & $5 \%(2 / 40)$ & 0 & $6.5 \%(6 / 93)$ \\
Trichuris trichiura & $12.5 \%(5 / 40)$ & $1.9 \%(1 / 53)$ & $1.1 \%(1 / 93)$ \\
Ascaris lumbricoides + Trichuris trichiura & 0 & $1.9 \%(1 / 53)$ & $6.5 \%(6 / 93)$ \\
Giardia duodenalis & $5 \%(2 / 40)$ & $7.5 \%(4 / 53)$ & $16.1 \%(15 / 93)$ \\
Infected & $22.5 \%(9 / 40)$ & $11.3 \%(6 / 53)$ & $1 \%(3)$ \\
\hline
\end{tabular}

Table 2. Intestinal parasitic infections distributed by age groups of 93 hospitalized children

\begin{tabular}{lccc}
\hline & $\begin{array}{c}\mathbf{0 - 1 2} \text { months } \\
(\mathbf{n}=\mathbf{4 8})\end{array}$ & $\begin{array}{c}\mathbf{1 2 - 2 4} \text { months } \\
(\mathbf{n}=\mathbf{3 3})\end{array}$ & $\begin{array}{c}>\mathbf{2 4} \text { months } \\
(\mathbf{n}=\mathbf{1 2})\end{array}$ \\
\hline Infected & $10.4 \%(5 / 48)$ & $12.1 \%(4 / 33)$ & $50 \%(6 / 12)$ \\
Ascaris lumbricoides & $2.1 \%(1 / 48)$ & 0 & $8.3 \%(1 / 12)$ \\
Trichuris trichiura & $4.2 \%(2 / 48)$ & $3 \%(1 / 33)$ & $25 \%(3 / 12)$ \\
Ascaris lumbricoides + Trichuris trichiura & 0 & 0 & $8.3 \%(1 / 12)$ \\
Giardia duodenalis & $4.2 \%(2 / 48)$ & $9 \%(3 / 33)$ & $8.3 \%(1 / 12)$ \\
Uninfected & $89.6 \%(43 / 48)$ & $87.9 \%(29 / 33)$ & $50 \%(6 / 12)$ \\
\hline
\end{tabular}


be infected than younger children who are still breastfed $[15,16]$

The frequency of infection obtained could be underestimated, considering one stool sample per child was collected; for instance, in the case of $G$. duodenalis, analysis of one stool sample allows for the detection of $60 \%$ to $80 \%$ of infections, two samples allow for $80 \%$ to $90 \%$ detection, and three samples allow for detection of over $90 \%$ of infections [17]. Furthermore, other potential enteric parasites, such as Cryptosporidium, are not detected through microscopy without a specific staining technique [18].

Children from the ICD ward were two times more infected when compared with children from the $\mathrm{MN}$ ward, especially with helminths.

Despite the limited number of samples tested, this is the first study that describes the frequency of intestinal parasites (including protozoa) in children hospitalized in one of the biggest hospitals of the town of Maputo in Mozambique.

The parasites detected in the present study may not be the main agents of diarrhea since other potential pathogens such as bacteria, viruses, or even other parasites are not detectable through microscopy. Nevertheless, this study suggests that in endemic regions such as Mozambique, the diagnosis of intestinal parasites in children should be performed routinely in hospitals in order to improve the health status of the children.

\section{Acknowledgements}

The authors are grateful to the children and respective guardians that participated in the study. We also want to thank the staff of the Maputo Central Hospital, particularly Maria Helena Ferreira, Paula Santos, and Beatriz Elias, for their collaboration with patient logistics, and the staff of the Faculty of Medicine of the University Eduardo Mondlane, particularly Titus Buene for his important technical support. We also would like to thank Jorge Atouguia, Jorge Seixas, and Luis Távora-Tavira of the Institute of Hygiene and Tropical Medicine, Lisbon, for their help with logistic issues and manuscript review.

Financial support for this work was provided by the Centro de Malária e outras Doenças Tropicais - Laboratório Associado (CMDT-LA).

\section{References}

1. World Health Organization (2013) Diarrhoeal disease. Fact sheet 330. Geneva: World Health Organization. Available at: http://www.who.int/mediacentre/factsheets/fs330/en/Accesse d 16 September 2013.

2. Cartmell E, Natalal H, François I, Ferreira MH, Grahnquist L (2005) Nutritional and clinical status of children admitted to the malnutrition ward, Maputo Central Hospital: A comparison of data from 2001 and 1983. J Trop Pediatr 51: 102-105.

3. World Health Organization (2006) Country Health System Fact Sheet, Mozambique Geneva: World Health Organization. Available at: http//www.afro.who.int/.../1271mozambique-country-health-system-fact-sheet-2006.html.

Accessed 12 April 2013.

4. World Health Orgnization (2009) Diarrhea: Why children are still dying and what can be done. Geneva: World Health Organization.

5. Berkman DS, Lescano AG, Gilman RH, Lopez SL, Black MM (2002) Effects of stunting, diarrhoeal disease, and parasitic infection during infancy on cognition in late childhood: a follow-up study. Lancet 359: 564-571.

6. Oberhelman RA, Guerrero ES, Fernandez ML, Silio M, Mercado D, Comiskey N, Ihenacho G, Mera R (1998) Correlations between intestinal parasitosis, physical growth, and psychomotor development among infants and children from rural Nicaragua. Am J Trop Med Hyg 58: 470-475.

7. Mandomando IM, Macete EV, Ruiz J, Sanz S, Abacassamo F, Vallès X, Sacarlal J, Navia MM, Vila J, Alonso PL, Gascon J (2007) Etiology of diarrhea in children younger than 5 years of age admitted in a rural hospital of southern Mozambique. Am J Trop Med Hyg 76: 522-527.

8. Augusto G, Nalá R, Casmo V, Sabonete A, Mapaco L, Monteiro J (2009) Geographic distribution and prevalence of schistosomiasis and soil-transmitted helminths among schoolchildren in Mozambique. A J Trop Med Hyg 81: 799803.

9. Guidetti C, Ricci L, Vecchia L (2011) Aetiology of intestinal parasites in a sample of students from Mozambique. Infez Med 3: 157-165.

10. Nhantumbo L, Maia JÁ, Santos FK, Jani IV, Gudo ES, Katzmarzyk PT, Prista A (2013) Nutritional Status and its association with physical fitness, physical activity and parasitological indicators in youths from rural Mozambique. Am J Hum Biol 25: 516-523.

11. Mbae CK, Nokes DJ, Mulinge E, Nyambura J, Waruru A, Kariuki S (2013) Intestinal parasitic infections in children presenting with diarrhoea in outpatient and inpatient settings in an informal settlement of Nairobi, Kenya. BMC Infectious Diseases 13: 243.

12. Sire JM, Garin B, Chartier L, Fall NK, Tall A, Seck A, Weill FX, Breurec S, Vray M (2013) Community-acquired infectious diarrhoea in children under 5 years of age in Dakar, Senegal. Paediatr Int Child Health 33: 139-144.

13. Nguyena NL, Gelayea B, Abosetb N, Kumiec A, Williamsa MA, Berhane Y (2012) Intestinal parasitic infection and nutritional status among school children in Angolela, Ethiopia. J Prev Med Hyg 53: 157-164.

14. Ritchie LS (1948) An ether sedimentation technique for routine stool examination. Bulletin of the United States Army Medical Department 8: 326.

15. Albonico M, Allen H, Chitsulo L, Engels D, Gabrielli AF, Savioli L (2008) Controlling soil-transmitted helminthiasis in 
pre-school-age children through preventive chemotherapy. PLoS Negl Trop Dis 2: 126.

16. Muniz-Junqueira MI, Oliveira Queiróz EF (2002) Relationship between protein-energy malnutrition, vitamin A, and parasitoses in children living in Brasília. Rev Soc Bras Med Trop 35: 133-141.

17. Gardner TB, Hill DR (2001) Treatment of giardiasis. Clin Microbiol Rev 14: 114-128.

18. De A (2013) Current laboratory diagnosis of opportunistic enteric parasites in human immunodeficiency virus-infected patients. Trop Parasitol 3: 7-16.

\section{Corresponding author}

Ana Maria Fonseca

Unidade de Clínica Tropical Instituto de Higiene e Medicina Tropical, Universidade Nova de Lisboa, Portugal

Current address: Barcelona Centre for International Health Research, CRESIB, Rosselló, 149, 1st floor, 08036 Barcelona. Spain

Email: amfonseca5@msn.com

Conflict of interests: No conflict of interests is declared 